\title{
Вторичные отложения и эволюция Онотских пещер (Восточный Саян)
}

\section{Базарова Е.П.}

Институт земной коры СО РАН, Иркутск, bazarova@crust.irk.ru

Аннотация. Вторичные минеральные образования Онотских пещер представлены агрегатами гравитационных и кораллитовых кор, сложенными кальцитом, арагонитом и гидромагнезитом, а также криогенными минеральными образованиями, сложенными икаитом и лансфордитом. Выделены четыре стадии развития пещер: первичной обводненности (1), снижения водопритока (2), вторичной обводненности (3) и современная стадия высыхания (4). На стадии снижения водопритока происходило отложение мощных натечных кор, сложенных кальцитом. После осушения пещер и формирования их современного облика началось отложение кораллитовых кор и криогенных минеральных образований, сложенных Mg-содержащими минералами.

Ключевые слова: пещеры, вторичные минералы, спелеотемы, Восточный Саян.

\section{Secondary deposits and evolution of the Onotskie caves (Eastern Sayan)}

\section{Bazarova E.P.}

Institute of the Earth Crust SB RAS, Irkutsk, bazarova@crust.irk.ru

\begin{abstract}
Secondary mineral formations of the Onotskie caves are represented by aggregates of gravitational and corallite crust, as well as cryogenic mineral formations. Secondary mineral formations are composed of calcite, aragonite and hydromagnesite. Cryogenic mineral formations are composed of ikaite and lansfordite. Four stages of caves evolution have been identified: primary flooding (1), decreasing water inflow (2), secondary flooding (3) and stage of drying out (4). After the draining of the caves and the formation of its modern form, the deposition of corallite crusts and cryogenic mineral formations began. These deposits are composed of Mg-containing minerals.
\end{abstract}

Key words: caves, secondary minerals, speleothems, Eastern Sayan.

Вторичные минеральные образования пещер несут информацию о степени обводненности, составе вмещающих пород, микроклимате и механизме образования подземных полостей. В свою очередь, условия в пещерах контролируются гидрогеологическими и климатическими условиями на поверхности. В данной работе рассматривается минеральный и химический состав спелеотем Онотских пещер, процессы привноса и выноса химических элементов при спелеолитогенезе и связь вторичных отложений с этапами эволюции карстовых полостей.

Онотские пещеры (Большая и Малая) находятся в Иркутской области в предгорьях Восточного Саяна, на правом берегу р. Онот, в нижней части скального выхода. Большая Онотская пещера имеет длину 226 м при амплитуде 60 м. В пещере два входа: основной - аркообразный, и дополнительный - трубообразный провал, под которым на полу пещеры находится конус около 10 м высотой, сложенный глинисто-щебнистым материалом. Пещера представляет собой прямой ход шириной от 4 до 10 м, приводящий в грот длиной 20 м при ширине до 16 м. Малая Онотская пещера имеет протяженность 136 м при амплитуде 8 м и представлена извилистым ходом с одним длинным и четырьми короткими ответвлениями (Вологодский, 1975). В обеих пещерах наблюдаются сезонные ледяные образования конжеляционного и сублимационного генезиса: сталактиты, сталагмиты, ледяные коры, изморозь. Лед формируется за счет просачивания воды сквозь кровлю по системе трещин и через верхний вход в Большой пещере.

Отбор образцов проводился в ходе тренировочно-исследовательского выезда в ноябре 2014 г. (руководитель Докучаев А.Г.). Были взяты образцы вмещающих пород и водно-хемогенных образований, сломавшихся естественным путем. Определение минерального состава образцов проводили в ЦКП Института земной коры СО РАН в г. Иркутске методом порошковой дифракции на рентгеновском дифрактометре ДРОН - 3.0 при условиях съёмки: излучение - $\mathrm{CuK \alpha}, \mathrm{Ni}-$ фильтр, $\mathrm{V}=25 \mathrm{\kappa B}$, $\mathrm{I}=20 \mathrm{мA}$, шаг сканирования $-0.05^{\circ}$ (аналитик Ущаповская 3.Ф.) и в Геологическом институте CO РАН в г. Улан-Удэ на микроскопе "LEO-1430VP" (Carl Zeiss International) с энергодисперсионным 
спектрометром «INCAEnergy 300» (Oxford Instruments Analytical Ltd.) при условиях анализа: ускоряющее напряжение 20 кВ, ток зонда 0.3-0.4 нА, размер зонда $<0,1$ мкм, время измерения 50 сек, ошибка +- 2 масс. \% (аналитик Хромова Е.А.). Определение химического состава образцов было выполнено в ЦКП Института земной коры СО РАН в г. Иркутске методом силикатного анализа (аналитик Самойленко М.М.).

Онотские пещеры приурочены к гидротермально измененным доломитам камчадальской свиты нижнего протерозоя. Доломиты от серого до темно-серого цвета, зачастую окварцованы, с включениями талька, плагиоклаза и хлорита. Содержание (среднее по 9 пробам, мас.\%) $\mathrm{SiO}_{2} 15.4, \mathrm{TiO}_{2}$ 0.18, $\mathrm{Al}_{2} \mathrm{O}_{3} 2.52, \mathrm{Fe}_{2} \mathrm{O}_{3}$ 1.04, $\mathrm{FeO} 1.45, \mathrm{MnO} 0.41, \mathrm{MgO} 21.48, \mathrm{CaO} 21.33, \mathrm{Na}_{2} \mathrm{O} 0.06, \mathrm{~K}_{2} \mathrm{O} 0.02, \mathrm{P}_{2} \mathrm{O}_{5}$ $0.04, \mathrm{CO}_{2} 32.09$, потери при прокаливании 3.65.

В пещерах наблюдается пять генетических типов (Максимович, 1963) вторичных образований: обвальные, водные механические, остаточные, водные хемогенные, а также криогенные образования. Обвальные образования сложены обломками вмещающих пород; водные механические осадки сформированы отложениями временных водотоков и представлены песчано-глинистыми и галечно-гравийными отложениями. Остаточные образования, сложенные нерастворимым остатком вмещающих пород, находятся в пещерах совместно с водными механическими и обвальными отложениями.

Водные хемогенные образования представлены агрегатами гравитационных и кораллитовых кор в соответствии с классификацией, основанной на способе подачи питающего раствора (Степанов, 1971; Мальцев, 1993). Агрегаты класса гравитационных кор в п. Большая Онотская представлены натечной корой мощностью до 1.5 м и длиной около 3.5 м, отпрепарированной в стенной нише в гроте (рис. 1 а) и натечными корами меньшей мощности. В п. Малая Онотская, кроме натечных кор, распространены драпировки и сталактиты. Минеральный состав агрегатов данного класса представлен кальцитом и арагонитом, также отмечаются отдельные мелкие включения кварца, гетита, плагиоклаза, биотита, мусковита, хлорита.

Кораллитовые коры наблюдаются преимущественно в Малой Онотской пещере и представлены кораллитами (рис. 1 б), иногда совместно с мелкими кристалликтитами. Кораллиты сложены Mg-содержащим кальцитом и арагонитом, иногда с гидромагнезитовыми обрастаниями. Присутствие магнезиального кальцита как основного минерала водных хемогенных образований Онотских пещер указывает на то, что образование арагонита в данных пещерах контролируется присутствием ионов Mg в питающем растворе. Формирование гидромагнезитовых обрастаний происходит при повышении концентрации $\mathrm{Mg}$ в растворе после выпадения из раствора кальцита и арагонита (Мальцев, 1993; Hill, Forti, 1997).

В составе кораллитов, особенно в нижних слоях, отмечаются многочисленные акцессорные минералы: кварц, гетит, доломит, магнетит, хлорит, апатит, рутил, гранат. Зачастую скопления этих зерен образует центры роста, вокруг которых отлагаются последующие слои кальцита (рис. 1 в). Выше в слоях кальцита наблюдаются также отдельные зерна магнетита, доломита, гетита, хлорита, талька и фторапатита. Зерна железистых минералов имеют как вытянутую игольчатую (рис. 1 г) или остроугольную обломочную форму, так и сглаженные очертания. Так как рутил может слагать мельчайшие новообразования в осадочных породах, богатых гидроокислами железа, алюминия и кремния (Бетехтин, 1950), то включение этого минерала в кальците кораллита Малой Онотской может иметь автохтонное происхождение. Апатит также может быть автохтонным, так как содержание фосфора в общем составе кораллита превышает его содержание во вмещающих породах. Доломит в спелеотемах Онотских пещер имеет форму, как обломочных зерен, так и слагает участки среди Mg-содержащего кальцита, что может указывать на его отложение из раствора с увеличением содержания иона Mg. Гетит является весьма распространенным пещерным минералом (Hill, Forti, 1997), зачастую образуется из других железосодержащих минералов и в кораллите является продуктом изменения магнетита. Прочие акцессорные минералы (кварц, плагиоклаз, слюды, хлорит, гранат) имеют, по-видимому, аллохтонное происхождение за счет глинистой примеси, захваченной кораллитом в процессе роста. 

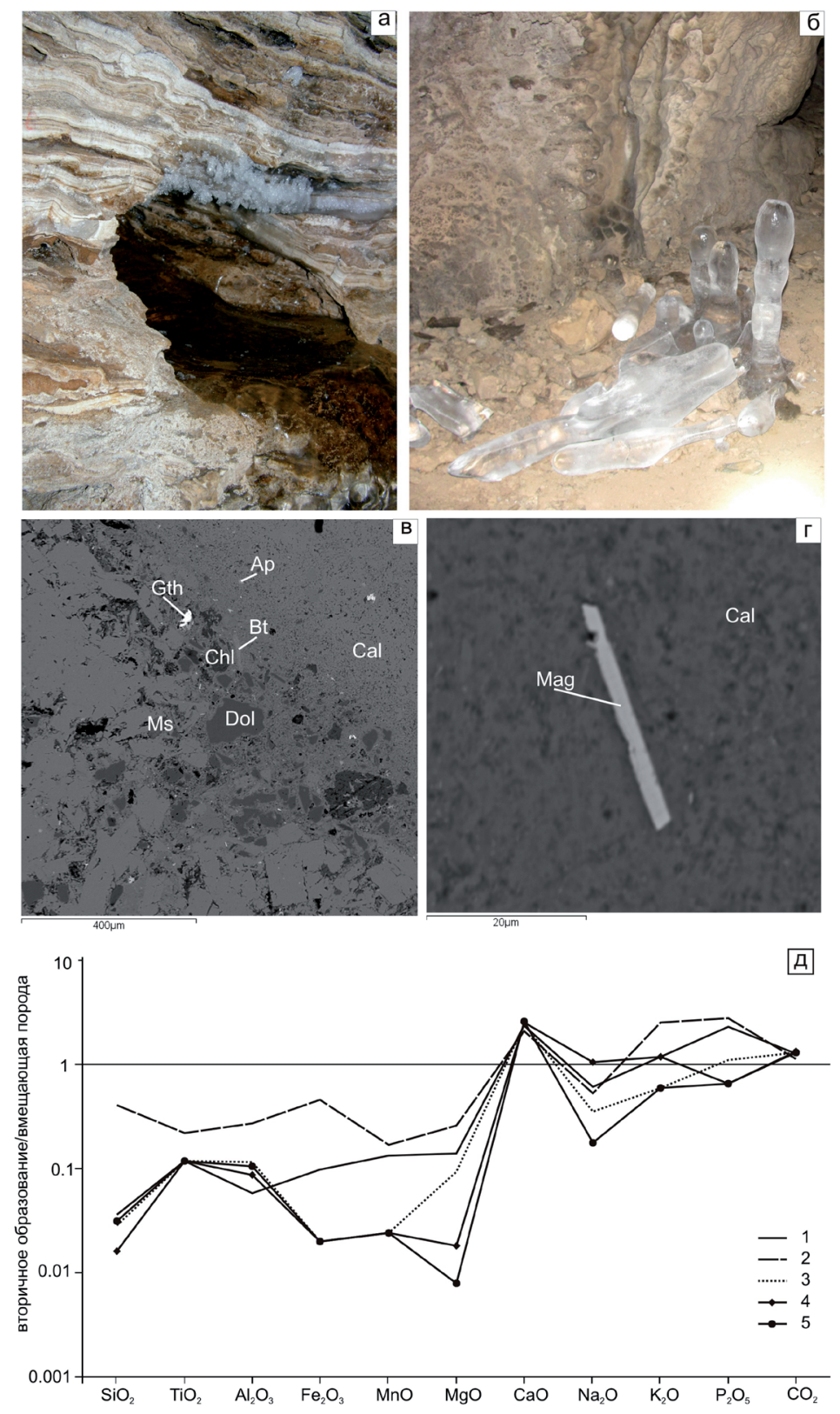

Рис. 1. В верхнем ряду - водные хемогенные образования (a - б): а - участок натечной коры, отпрепарированной в стене грота в п. Большая Онотская (фотография С.Ю. Пономарева), б - мелкие кораллиты на стене в п. Малая Онотская (фотография А.Г. Докучаева). На стенах и на полу обеих пещер видны ледяные образования. В среднем ряду - внутреннее строение кораллита (в - г): в - скопление зерен, слагающих центр роста кораллита, г - игольчатое включение магнетита в кальците (Ap - фторапатит, Ms - мусковит, Cal - кальцит, Dol - доломит, Gth - гетит, Bt - биотит, Chl - хлорит, Mag - магнетит). Внизу - график относительных концентраций петрогенных компонентов в составе вторичных образований Онотских пещер. Малая Онотская: 1 - натечные коры, 2 - кораллиты, 3 - сталактит; Большая Онотская: 4 - натечная кора, 5 - натечная кора, вскрытая в стенной нише.

Fig. 1. In the upper row - water chemogenic formations $(a-b)$ : $a-a$ section of the flowstone, prepared in the wall of the grotto in the Bolshaya Onotskaya cave (photo by S.Yu. Ponomarev), b-small corallites on the wall in the Malaya Onotskaya cave (photo by A.G. Dokuchaev). Ice formations are visible on the walls and on the floor of the caves. In the middle row - internal structure of corallite $(c-d)$ : $c$ - accumulation of mineral grains composing the center of growth of corallite, $\mathrm{d}$ - acicular inclusion of magnetite in calcite (Ap - fluorapatite, Ms - muscovite, Cal - calcite, Dol - dolomite, Gth - goethite, Bt - biotite, Chl - chlorite, Mag - magnetite). In the bottom row - a graph of the relative concentrations of petrogenic components in the secondary formations of the Onotskie caves. Malaya Onotskaya cave: 1 - flowstone, 2 - corallites, 3 - stalactite; Bolshaya Onotskaya cave: 4 - flowstone, 5 - flowstone, prepared in the wall niche. 
a)

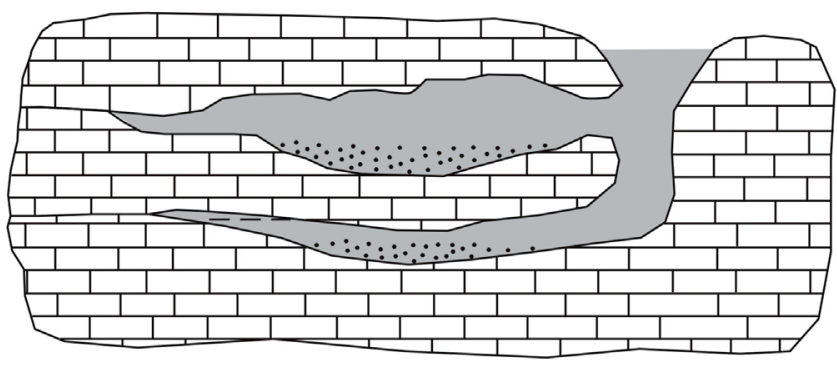

б)

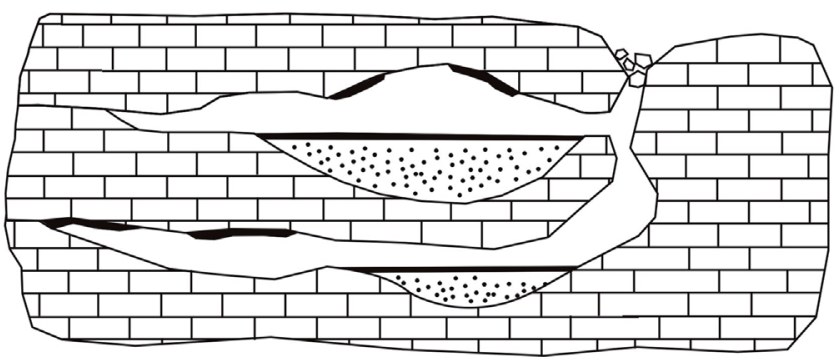

B)

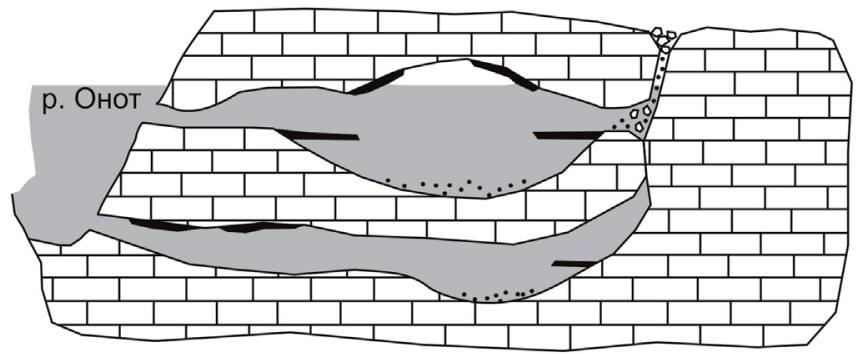

г)

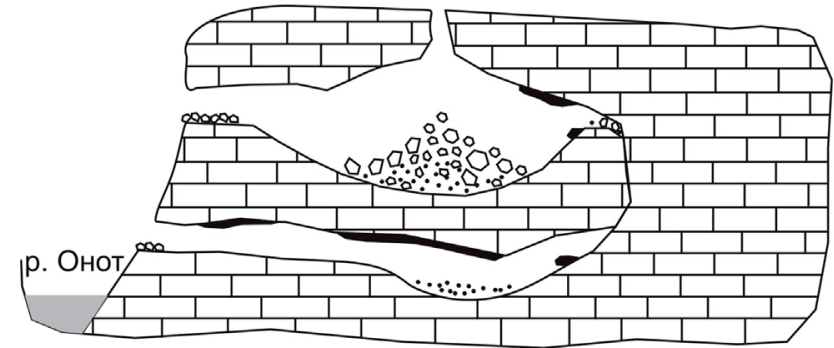

Условные обозначения

$\therefore \because$ б а - песчано-глинистые отложения

а ovd 6 - обвальные отложения

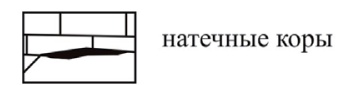

Рис. 2. Схема этапов развития и заполнения вторичными отложениями Онотских пещер: а - образование первичной полости и отложение рыхлого песчано-глинистого материала; б - уменьшение водопритока и цементация аллювиальных отложений вторичным кальцитом; в - вскрытие пещер рекой Онот и частичное вымывание заполнителя; г - формирование современного облика пещер.

Fig. 2. Scheme of the stages of evolution and filling of secondary sediments of the Onotskie caves: a - formation of a primary cave and deposition of loose sandy-clayey material; $b$ - decrease of water inflow and cementation of alluvial deposits of secondary calcite; $\mathrm{c}$ - opening of caves by Onot River and partial washing out of the loose deposits; $d$ - the formation of the modern appearance of the caves.

Криогенные минеральные образования наблюдаются преимущественно в п. Большая Онотская в виде мелкокристаллического порошка (так называемая криогенная пудра) на поверхности ледяных образований и в минеральном отношении сложены икаитом и лансфордитом. Подробно данные образования были рассмотрены в работе (Базарова и др., 2016). 
Для исследования процессов перераспределения элементов при спелеолитогенезе был построен график относительных концентраций петрогенных компонентов во вторичных образованиях (рис. 1 д). В целом в хемогенных образованиях происходило накопление $\mathrm{CaO}$ и $\mathrm{CO}_{2}$, в отдельных случаях $\mathrm{K}_{2} \mathrm{O}$ и $\mathrm{P}_{2} \mathrm{O}_{5}$, вероятно засчет включений апатита и слюд, прочие компоненты выносятся. Наибольшим обеднением химического состава отличаются образцы натечной коры из п. Большая Онотская, особенно слои вторичного кальцита, вскрытые в стене грота. В отличие от прочих хемогенных образований, данная натечная кора содержит только 0.17 мас. \% $\mathrm{MgO}$, что указывает на относительно невысокие концентрации $\mathrm{Mg}$ в растворе. Кораллиты и натечные коры из п. Малая Онотская отличаются повышенным, по сравнению с другими агрегатами, содержанием $\mathrm{MgO}$ (до 4.34 мас. \%).

По результатам исследования вторичных отложений можно предположить следующую схему формирования и развития пещер и выделить характерные особенности осадконакопления в них.

На раннем этапе по трещинам в массиве вмещающих пород была образована исходная полость (рис. 2 a), которая служила активным водотоком и частично заполнилась рыхлым аллювиальным материалом. При падении уровня грунтовых вод и уменьшении скорости течения и притока раствора рыхлые образования были сцементированы кальцитом и глиной. Поверх толщи аллювиальных отложений сформировались мощные кальцитовые коры, реликт которых на сегодняшний день наблюдается в стенной нише грота в Большой Онотской пещере (рис. 2 б). В дальнейшем при углублении долины р. Онот произошло вскрытие и вторичное затопление пещерной системы (рис. 2 в), вследствие чего часть рыхлого заполнителя была размыта и вынесена, но при этом сохранились отдельные участки древних натечных кор. Обвалы в пещере вследствие резкого увеличения водопритока и гравитационных склоновых процессов привели к разделению исходной полости на отдельные пещеры (рис. 2 г) и образованию второго входа в п. Большая Онотская. После ослабления водопритока в обеих пещерах вновь началось отложение агрегатов гравитационных, а также кораллитовых и кристалликтитовых кор. Присутствие магнезиальных минералов (Mg-кальцит, гидромагнезит) указывает на повышение содержания $\mathrm{Mg}$ в растворе на данном этапе хемогенного осадконакопления в пещерах. Современное минералообразование представлено формированием сезонных криогенных образований и мелких кораллитов на отдельных участках пещер.

В дальнейшем планируется получение геохронологических данных по древним натечным корам из Большой пещеры, что даст информацию о примерном времени вскрытия пещер рекой и, соответственно, об этапах формирования современного ландшафта на данной территории.

\section{Благодарности}

Автор благодарит А.Г. Докучаева за помощь в сборе образцов и аналитиков 3.Ф. Ущаповскую, Е.А. Хромову и М.М. Самойленко за проделанные анализы.

\section{Литература}

1. Базарова Е.П., Кадебская О.И., Кононов А.М., Ущаповская З.Ф. Условия и особенности криогенного минералообразования в пещерах южной части складчатого обрамления Сибирской платформы (Западное Прибайкалье и Восточный Саян) // Вестник Пермского университета. Геология. 2016. Вып. 2 (31). C. 22-34. DOI: 10.17072/psu.geol.30.22.

2. Бетехтин А.Г. Минералогия. М. Изд-во: Госгеолиздат. 1950. 956 c.

3. Вологодский Г.П. Карст Иркутского амфитеатра. М. Изд-во: Наука. 1975. 124 с.

4. Максимович Г.А. Основы карстоведения. Т. 1. Пермь. 1963. 445 с.

5. Мальцев В.А. Минералы системы карстовых пещер Кап-Кутан (юго-восток Туркменистана) // Мир Камня (World of Stones). 1993. № 2. http://www.vl-maltsev.narod.ru.

6. Степанов В.И. Периодичность процессов кристаллизации в карстовых пещерах // Труды минералогического музея им. Ферсмана. Вып. 20. Москва. 1971. С. 161-171.

7. Hill C., Forti P. Cave minerals of the world. Huntsville. USA.1997. 463 p. 